\title{
Central nervous system effects of the interaction
} between risperidone (single dose) and the $5-\mathrm{HT}_{6}$ antagonist SB742457 (repeated doses) in healthy men

\section{Correspondence}

Mrs Marieke Liem-Moolenaar, Centre for Human Drug Research, Zernikedreef 10, $2333 \mathrm{CL}$ Leiden, the Netherlands.

Tel.: + 31715246400

Fax: + 31715246499

E-mail:mmoolenaar@chdr.nl

Keywords

$5-\mathrm{HT}_{6}$ antagonist, CNS effects, healthy volunteers, risperidone

Received

17 June 2010

Accepted

24 December 2010

Accepted Article

11 January 2011

Marieke Liem-Moolenaar, ${ }^{1}$ Mandana Rad, ${ }^{1}$ Stefano Zamuner, ${ }^{2}$

Adam F. Cohen, ${ }^{1}$ Francesca Lemme, ${ }^{3}$ Kari L. Franson, ${ }^{1}$

Joop M. A. van Gerven ${ }^{1} \&$ Emilio Merlo Pich ${ }^{4}$

${ }^{1}$ Centre for Human Drug Research, Leiden, the Netherlands, ${ }^{2}$ Clinical Pharmacokinetics, Modelling and

Simulation, ${ }^{3}$ Biometrics and ${ }^{4}$ Discovery Medicine, Psychiatry CEDD, GlaxoSmithKline, Research

Medicine Centre, Verona, Italy

\section{WHAT IS ALREADY KNOWN ABOUT THIS SUBJECT}

- Several lines of evidence suggest a possible role of $5-\mathrm{HT}_{6}$ receptor antagonists in dementia or cognitive dysfunction of schizophrenia. SB-742457 is a potent $5-\mathrm{HT}_{6}$ antagonist and has shown efficacy in different animal models of cognitive impairment. It is currently in development as a cognitive enhancer. Risperidone, commonly used to control agitation and psychotic features in both schizophrenia and Alzheimer's disease, is a $D_{2} / 5$ $\mathrm{HT}_{2 \mathrm{~A}}$ antagonist with low affinity for $5-\mathrm{HT}_{6}$ receptors and limited effects on cognitive parameters.

\section{WHAT THIS STUDY ADDS}

- As the combination of risperidone and SB-742457 may constitute a reasonable combination in cognitively impaired patients, pharmacodynamic interaction effects were investigated in this study. The only significant drug-drug interaction was a small increase of electroencephalogram (EEG) alpha and beta bands, which might suggest mild arousing activity of SB-742457 on the central nervous system-depressant effects of risperidone. The clinical relevance of these findings in patients remains to be established. Additionally, this study provided an extensive multidimensional pharmacodynamic profile of risperidone in healthy volunteers, showing that this antipsychotic suppresses motor performance (eye-hand coordination, finger tapping and postural stability), alertness, memory and neurophysiological functions (saccadic eye movements and EEG power spectrum).

\section{AIM}

Several lines of evidence suggest a possible role of $5-\mathrm{HT}_{6}$ receptor antagonists in cognitive dysfunction of schizophrenia. Atypical antipsychotics, such as risperidone, are currently used in these disorders. Therefore, the pharmacological interactions between the $5-\mathrm{HT}_{6}$ antagonist SB-742457 and risperidone were investigated in the light of possible co-medication.

\section{METHODS}

A randomized, double-blind, two-way crossover design was used to study the interaction between multiple doses SB-742457 $50 \mathrm{mg}$ and a single dose risperidone $2 \mathrm{mg}$ in 18 healthy subjects.

\section{RESULTS}

Treatment was well tolerated. The most common adverse event was somnolence in $83 \%$ during the combination vs. $50 \%$ of subjects after risperidone, $32 \%$ after placebo and $11 \%$ after SB-742457. Combination treatment produced a statistically significant increase in the maximum plasma concentration of risperidone and had no effect on SB-742457 pharmacokinetics. Risperidone decreased saccadic peak velocity, finger tapping, adaptive tracking, subjective alertness, delayed word recognition and body sway and increased electroencephalogram (EEG) theta power and prolactin. The only pharmacodynamic interaction of risperidone and SB-742457 was an increase of absolute EEG alpha (ratio $=1.25,95 \% \mathrm{Cl}=1.11,1.40, P=0.0004$ ) and beta power (ratio $=1.14,95 \% \mathrm{Cl}=1.03,1.27, P=0.016$ ). No significant effects of SB-742457 alone were found.

\section{CONCLUSION}

The pharmacokinetic interactions between SB-742457 and risperidone detected in this study were not clinically relevant. The increase in EEG alpha and beta power is incompatible with enhanced risperidone activity, but could point to mild arousing effects of the combination. Most pharmacodynamic changes of risperidone are consistent with previously reported data. The potential cognitive effects of SB-742457 remain to be established. 


\section{Introduction}

Several recent lines of evidence have suggested a role of 5-hydroxytryptamine $6\left(5-\mathrm{HT}_{6}\right)$ receptors in cognitive and memory processes. Improvements in memory and other aspects of cognition have been reported using different $5-\mathrm{HT}_{6}$ antagonists, both in healthy animals and in animal models of cognitive impairment [1-7]. Several research groups have suggested that $5-\mathrm{HT}_{6}$ blockade may be involved in learning and memory via increased cholinergic transmission [5, 7-10] or modulation of dopaminergic transmission [11], but secondary changes in noradrenergic and glutamatergic neurotransmission may also be involved $[12,13]$. Preliminary data from studies in patients with Alzheimer's disease (AD) suggest that the beneficial effects of treatments with $5-\mathrm{HT}_{6}$ receptor antagonists seen in animal models may translate into humans $[14,15]$.

In schizophrenia, the role of the $5-\mathrm{HT}_{6}$ receptor is less well defined. There is post-mortem evidence of reduced expression of the $5-\mathrm{HT}_{6}$ receptor in the hippocampus of schizophrenic patients [16]. Some of the most effective antipsychotic drugs partially bind to $5-\mathrm{HT}_{6}$ receptors, and $5-\mathrm{HT}_{6}$ receptors have been shown to be down-regulated by prolonged clozapine treatment in rats [17]. However, it is unknown if the reduced expression of $5-\mathrm{HT}_{6}$ receptors is due to the disease or chronic treatment.

At present, over a dozen selective $5-\mathrm{HT}_{6}$ antagonists are at various stages of development [14]. SB-742457 is a potent $5-\mathrm{HT}_{6}$ antagonist $(\mathrm{pKi}=9.6)$ with high affinity for human $5-\mathrm{HT}_{2 \mathrm{~A}}$ receptors $(\mathrm{pKi}=8.0$; for structural formula see Figure 1). SB-742457 has shown efficacy in different animal models of cognitive impairment [14]. In humans, reports that SB-742457 is of clinical benefit in AD patients provided further evidence of the therapeutic potential of this approach $[18,19]$. Repeated-dose studies in healthy subjects receiving daily $50 \mathrm{mg}$ showed low occurrence of mild adverse events (AEs), mostly headache. At this dose, the exposure to SB-742457 is expected to deliver $5-\mathrm{HT}_{6}$ receptor occupancy of the central nervous system (CNS) above $90 \%$ (unpublished data). Clinical pharmacokinetic assessment showed that SB-742457 has a half-life of approximately $30 \mathrm{~h}$, reaching steady state after 7 days with an accumulation ratio of about fourfold (unpublished data and [14]). Preclinical investigations showed that SB-742457 is a moderate inhibitor of CYP450 3A4.

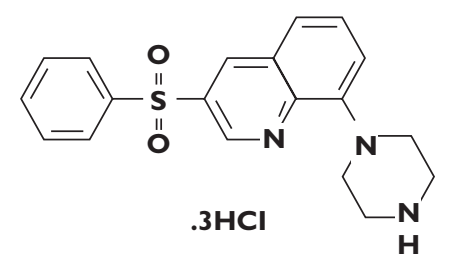

Figure 1

Structural formula of SB-742457
For schizophrenia, SB-742457 would be considered for development as an add-on treatment to be used in combination with antipsychotic drugs (e.g. risperidone), known for their lack of clinical effect on cognition [20]. Risperidone is a dopamine $2\left(\mathrm{D}_{2}\right) / 5-\mathrm{HT}_{2 \mathrm{~A}}$ antagonist with low affinity for $5-\mathrm{HT}_{6}$ receptors and limited effects on cognitive parameters [21] and is commonly used to control agitation and psychotic features. Therefore, the combination of risperidone and SB-742457 may constitute a reasonable combination in cognitively impaired patients. Risperidone is known to produce a series of CNS effects (such as sedation, increased theta band power of the electroencephalogram (EEG) spectra and increased prolactin concentrations) at doses of $1-2 \mathrm{mg}$ in healthy volunteers [22]. It is primarily metabolized by CYP2D6, but CYP3A4 is also involved [23]. The main metabolite of risperidone is 9-hydroxyrisperidone, an active compound with a half-life of approximately $20 \mathrm{~h}$ [24]. The well-known profile of CNS effects may contribute to the cognitive impairment and the negative syndrome complex in some patients. As $5-\mathrm{HT}_{6}$ activity modulates dopaminergic transmission [11], it is hypothesized that some of the CNS effects due to neuroleptic agents are partially reversed by a $5-\mathrm{HT}_{6}$-antagonist like SB-742457. In this study the pharmacokinetic and pharmacodynamic effects of the interaction between SB-742457 and risperidone and of SB-742457 and risperidone alone were investigated in healthy volunteers. In this early stage of development of SB-742457, the pharmacodynamic effects had not been examined in humans, and its effects on risperidone could not be accurately predicted. Therefore, a multimodal test battery was used repeatedly, consisting of validated neurophysiological and neuropsychological tests. These tests have no direct bearing on schizophrenia and they only partly reflect the negative cognitive and behavioural) effects of this condition (and the positive psychotic effects even less). However the battery accurately covers most drug-responsive CNS-functional domains, and therefore had a large chance of demonstrating pharmacodynamic changes induced by risperidone or SB-742457 alone, or the effects of their combination.

\section{Methods}

\section{Volunteers}

Twenty-four healthy male volunteers aged between 18 and 38 years with a bodyweight above $50 \mathrm{~kg}$ and a body mass index between $18.5-29.9 \mathrm{~kg} \mathrm{~m}^{-2}$ were recruited for the study, with the aim of completing all treatments in at least 18 subjects. Subjects were considered 'healthy' by a responsible study physician, when no clinically significant abnormalities were identified on the medical or laboratory evaluation (haematology, biochemistry, virology, urinalysis and urine drug screen), blood pressure and heart rate or 12-lead ECG before the study starts medical. Exclusion criteria included the use of agents known to affect CNS func- 
tions (including drug or alcohol use), smoking more than five cigarettes a day and unable to refrain from smoking during the stay in the research unit. The Ethics Review Board of the Leiden University Medical Centre approved the study protocol. Written informed consent was obtained from all volunteers following a written and oral explanation.

\section{Study design}

This was a randomized, double-blind, double-dummy placebo controlled crossover study, consisting of two 11-day multiple dosing periods for either SB-742457 $50 \mathrm{mg}$ or placebo (see Figure 2). On days 8 and 9 of each period, a single dose of risperidone $2 \mathrm{mg}$ or placebo was administered in a balanced randomized crossover fashion. In this way, the effects of risperidone (either alone or with SB-742457) could be examined after acute administration (on day 8 or on day 9 after placebo treatment on the preceding day). There was at least 1 week washout between the two multiple-dose periods. Subjects received SB-742457 from day 1 until day 11. They visited the research centre in the morning on days 1 to 7 and days 11 to 14 and remained in house from the morning of day 8 until the morning of day 10. Both SB-742457 (capsule) and risperidone (tablet) or their matching placebos were administered once daily with a glass of water.

Before administration of the study medication all participants were instructed to remain fasted. Smoking was not allowed during the study days, volunteers refrained from alcohol and xanthine-containing foods or beverages from $24 \mathrm{~h}$ before each study period until day 12, and grapefruit products were not allowed from 14 days prior to the study until the end of the study.

\section{Pharmacokinetics}

Blood samples (approximately $3 \mathrm{ml}$ ) were obtained predose on days 6 and 7 (for SB-742457 measurements only), and days 10, 11 and 12 (for SB-742457, risperidone and 9-hydroxyrisperidone measurements). On days 8 and 9, blood samples were taken for SB-742457, risperidone and 9-hydroxyrisperidone at baseline and 45, 80, 140, 190, 235, $345 \mathrm{~min}$ and 8 and $12 \mathrm{~h}$ after administration of both drugs.

Plasma samples were analysed for SB-742457 by Drug Metabolism and Pharmacokinetics, GlaxoSmithKline, Ware, UK, using a validated analytical method based on protein precipitation, followed by high performance liquid chromatography/tandem mass spectrometry (HPLC/MS/ MS) analysis. The lower limit of quantification (LLQ) for SB-742457 was $1 \mathrm{ng} \mathrm{ml}^{-1}$, using a $50 \mu \mathrm{l}$ aliquot of EDTA plasma with a higher limit of quantification (HLQ) of $5000 \mathrm{ng} \mathrm{ml}^{-1}$. Plasma samples were analysed for risperidone and 9-hydroxyrisperidone by York Bioanalytical Solutions, York, UK, using a validated analytical method based on protein precipitation, followed by HPLC-MS/MS analysis. The LLQ for both risperidone and 9-hydroxyrisperidone was $0.1 \mathrm{ng} \mathrm{ml}^{-1}$, using a $50 \mu \mathrm{l}$ aliquot of human plasma with a HLQ of $100 \mathrm{ng} \mathrm{ml}^{-1}$ [25].

Quality control (QC) samples, prepared at three different analyte concentrations and stored with study samples, were analysed with each batch of samples against separately prepared calibration standards. For the analysis to be considered acceptable, no more than onethird of the QC results deviated from the nominal concentration by more than $15 \%$, and at least $50 \%$ of the results from each QC concentration were within 15\% of nominal. The applicable analytical runs met all predefined run acceptance criteria.

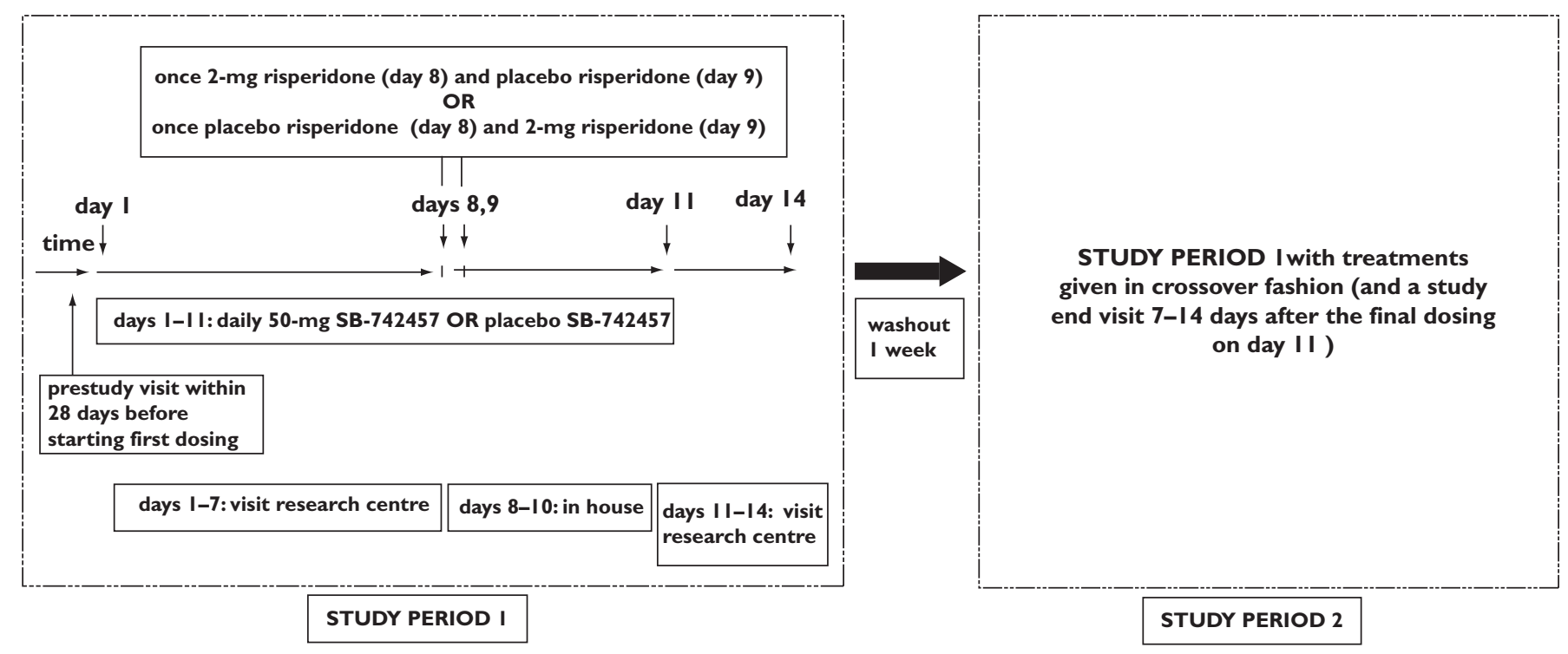

Figure 2

Scheme of study periods 1 and 2, which were similar and separated by at least 1 week washout 


\section{Pharmacodynamics}

On days 8 and 9, a pharmacodynamic test battery was performed twice at baseline and 45, 80, 140, 190, 235, 295, $345 \mathrm{~min}$ and 8 and $12 \mathrm{~h}$ after administration of both drugs. The battery takes about 20 min and consists of the pharmacodynamic assessments described below, which were performed in a quiet room with subdued light with one volunteer per room. No more than 1 week before the start of the study, the volunteers were familiarized with the test procedures during a training session.

\section{Pharmaco-electroencephalography}

Pharmaco-EEG was performed as a general measure of CNS activity [26]. The literature suggests that antipsychotics produce distinct profiles of EEG changes [27, 28]. EEG recordings were made using silver chloride electrodes, fixed with collodion at $\mathrm{Fz}, \mathrm{Cz}, \mathrm{Pz}$ and $\mathrm{Oz}$ (international 10/20 system), as previously described [29]. Fast Fourier transform analysis was performed to obtain the sum of amplitudes in the delta- $(0.5-3.5 \mathrm{~Hz})$, theta- $(3.5-7.5 \mathrm{~Hz})$, alpha- $(7.5-11.5 \mathrm{~Hz})$ and beta- $(11.5-30 \mathrm{~Hz})$ frequency ranges. The square root of the total power $(\mu \mathrm{V})$ was analysed. The duration of one EEG recording was $64 \mathrm{~s}$ (i.e. eight blocks of $8 \mathrm{~s}$ ).

\section{Saccadic and smooth pursuit eye movements}

Eye movements were recorded as previously described $[30,31]$ and have shown effects with many different CNS active compounds, including GABA-ergic [22, 32, 33], serotonergic [34], noradrenergic [35-37] and dopaminergic agents $[22,29]$. For saccadic eye movements, the average values of latency (reaction time), saccadic peak velocity and inaccuracy of all artifact free saccades were calculated. The average percentage of smooth pursuit for all stimulus frequencies was used.

\section{Adaptive tracking}

The adaptive tracking test has proved to be useful for measurement of the CNS effects of alcohol [38], various psychoactive drugs [26, 39] and sleep deprivation [30, 38]. It measures visuo-motor coordination and vigilance and was performed as originally described by Borland [39], using customized equipment and software (Hobbs, 2000, Hertfordshire, UK). The average performance scores over a 3-min period were used for analysis, as described previously [29].

\section{Body sway}

Changes in body sway have been seen for many different CNS active drugs, including GABA-ergic compounds [32, 33], dopaminergic agents [29] and tetrahydrocannabinol (THC) [40]. The body sway allows measurement of body movements in a single plane, providing a measure of postural stability. Body sway was measured with an apparatus similar to the Wright ataxiameter [28]. With a string attached to the waist, all body movements over a period of 2 min were integrated and expressed as millimetre sway on a digital display. Measurements of body sway were made in the sagittal planes. All assessments were made with the eyes closed, standing with feet $10 \mathrm{~cm}$ apart wearing comfortable low-heeled shoes. The total amount of movement was used for statistical analysis.

\section{Subjective assessments}

Visual analogue scales (VAS) consist of $100 \mathrm{~mm}$ line segments. Subjects put a mark on a point on the line that best represents their subjective state corresponding to the condition tested. The result is a distance $(\mathrm{mm})$ calculated from the mark on the line.

Subjective effects were quantified using a Dutch translation of the 16VAS originally described by Norris [41].They have been used previously to quantify subjective effects of a variety of agents, including sedative [32,33], dopaminergic drugs $[22,29]$, scopolamine (Centre for Human Drug Research data on file) and THC [40]. From these measurements, three factors are derived as described by Bond and Lader [42], corresponding to alertness, mood and calmness $[32,33,43]$. A lower score on these scales indicates sedation, excitation and decrease in mood (or contentedness) respectively.

A translated version of the Bowdle psychotomimetic VAS [44] showed effects of THC [40], zolpidem [43] and scopolamine (Centre for Human Drug Research data on file). The lowest extreme is ' 0 ', signifying complete absence of the state (which is the case under normal circumstances), the highest the 'most extreme state imaginable'. The VAS scores were performed electronically using custom-written and validated E-prime scripts (http:// www.pstnet.com/eprime.cfm).

\section{Finger tapping}

The finger tapping test was adapted from the Halstead Reitan Test Battery [45]. The test evaluates motor activation and fluency. Speed of finger tapping was measured for the index finger of the dominant hand; a session contained five performances of $10 \mathrm{~s}$. The volunteer was instructed to tap as quickly as possible on the space bar of a keyboard. The mean tapping rate and the standard deviations are used for statistical analysis.

\section{Visual Verbal Learning Test}

Memory includes many different components of learning behaviour, such as acquisition, consolidation, storage and retrieval. The Visual Verbal Learning Test (VVLT) contains three different subtests that cover most of the scope of learning behaviour, i.e. immediate and delayed word recall and a delayed word recognition [46]. This test is a modified version of the auditory verbal learning test [47] in which 30 words are shown. This test is known to be sensitive to the CNS effects of various compounds such as benzodiazepines [32], cannabinoids [40] and scopolamine [48]. The 
outcome measures for the immediate and delayed word recall were the average and the maximum number of correct responses. For the delayed word recognition, the number of correct items and mean response time for correct responses were recorded.

\section{Plasma prolactin concentrations}

Prolactin increase induced by antipsychotics is closely related to $\mathrm{D}_{2}$-receptor antagonism [22]. Prolactin concentrations were measured predose and at 30,45, 60, 80, 140, $190,235,345 \mathrm{~min}$ and $8 \mathrm{~h}$ after administration of both drugs as described previously. For this purpose, blood samples were collected in plain 3-ml tubes and kept at room temperature for 30 to $45 \mathrm{~min}$. Serum was separated by refrigerated centrifugation $\left(2000 \mathrm{~g}\right.$ at $4^{\circ} \mathrm{C}$ for $10 \mathrm{~min}$ ) within $1 \mathrm{~h}$ of collection and transferred to polypropylene tubes. Serum specimens were stored at approximately $-20^{\circ} \mathrm{C}$ until analysis. The hormone assays were performed by the Central Clinical Chemistry Laboratory of the Leiden University Medical Center and were performed by electrochemiluminescence immunoassay on a Modular Analytics E170 (Elecsys module) immunoassay analyser. The assay had a LLQ of $0.047 \mu \mathrm{gl}^{-1}$, an intra-assay precision (expressed as coefficient of variation) of $1.81-1.90 \%$ and inter-assay precision of $2.39-2.64 \%$.

\section{Statistical analysis}

Pharmacokinetic analysis Pharmacokinetic analyses of plasma SB-742457, risperidone, 9-hydroxyrisperidone and total risperidone active moiety concentration-time data were conducted using non-compartmental methods.

Main pharmacokinetic endpoints were maximum observed concentration $\left(C_{\max }\right)$ and area under the plasma concentration-time curve up to last time point $[\operatorname{AUC}(0, t)]$ and extrapolated to infinity $[\operatorname{AUC}(0, \infty)]$ of risperidone and 9-hydroxy-risperidone, while $C_{\max }$ and $A U C$ over the dosing interval were evaluated for SB-742457. Plasma concentration-time data were evaluated by standard noncompartmental analysis using WinNonlin Professional Version.

The study sample size was based on feasibility. A variability estimate of 0.32 for $\operatorname{AUC}(0, \infty)$ of risperidone was taken from published results for a risperidone/venlafaxine interaction study [49]. With such variability, it was estimated that with 16 evaluable subjects (of the 20 recruited) completing the study, the lower and upper limits of the $90 \%$ confidence interval $(\mathrm{Cl})$ for the ratio of geometric means (ratio of SB-742457 + risperidone and placebo + risperidone) would have been within $20.9 \%$ of the point estimate. In practice, assuming a true ratio of 1 , this precision would have lead to a $90 \% \mathrm{Cl}$ of 0.83 to 1.21 .

Following log transformation, total risperidone (active moiety) $\operatorname{AUC}(0, t), \operatorname{AUC}(0, \infty)$ and $C_{\max }$ and SB-742457 $\operatorname{AUC}(0, \tau)$ and $C_{\max }$ were analysed using a mixed effects model with session, day, regimen and regimen $\times$ day as fixed effects and subject as a random effect. Point esti- mates and corresponding 90\% Cls for the differences between risperidone in presence of SB-742457 compared with risperidone in presence of placebo were obtained using the residual variance from ANOVA. These data were then exponentially back-transformed to give estimates of the ratios of geometric means and $90 \%$ Cls. Lack of drug interaction between SB-742457 and risperidone would have been demonstrated if the $90 \% \mathrm{Cl}$ was completely contained within $0.80,1.25$.

Pharmacodynamic analysis This analysis was exploratory and the formal power estimate was performed according to pharmacokinetic criteria (see above). However, past experience at the study site and published information on EEGs indicated that pharmacodynamic signals could be seen using 8-12 subjects. All endpoints were analysed using an ANOVA model, which was fitted using PROC MIXED in SAS. For VVLT and prolactin endpoints, the model included session, day, regimen, day $\times$ regimen, and, when available, baseline as fixed effect terms and subjects as a random effect term. For all other endpoints, the model included session, day, regimen, time, day $\times$ regimen, time $\times$ regimen and day $\times$ time $\times$ regimen as fixed effect terms and subjects and subject $\times$ session $\times$ day as random effect terms.

The following Least Square Means differences were computed to investigate the related treatment effect:

- Risperidone effects: placebo SB-742457 + risperidone (day 9) vs. placebo SB-742457 + placebo risperidone (day 8).

-SB-742457 effects: SB-742457 + placebo risperidone (day 8) vs. placebo SB-742457 + placebo risperidone (day 8).

- Effects of SB-742457 co-administration on risperidone effects:SB-742457 + risperidone (days 8 and 9) vs. placebo SB-742457 + risperidone (days 8 and 9).

No correction for multiple comparisons among the various endpoints was performed as this analysis was considered exploratory.

\section{Results}

\section{Study population}

Twenty-four volunteers were included in the study and six volunteers were withdrawn from the study, resulting in 18 completers. Three subjects withdrew for non drug-related AEs, one for protocol violation, one for personal reasons and one because of a rash (during placebo, see below). Volunteers had a mean (min-max) age of 24.8 (18-38) years, were healthy and took no relevant concomitant medications.

\section{Tolerability}

No clinically significant changes were observed for vital signs, respiratory functions, physical examination or 


\section{Table 1}

Adverse events (AEs) reported on days 8 and 9 after SB-742457, risperidone, the combination of SB-742457 and risperidone and placebo

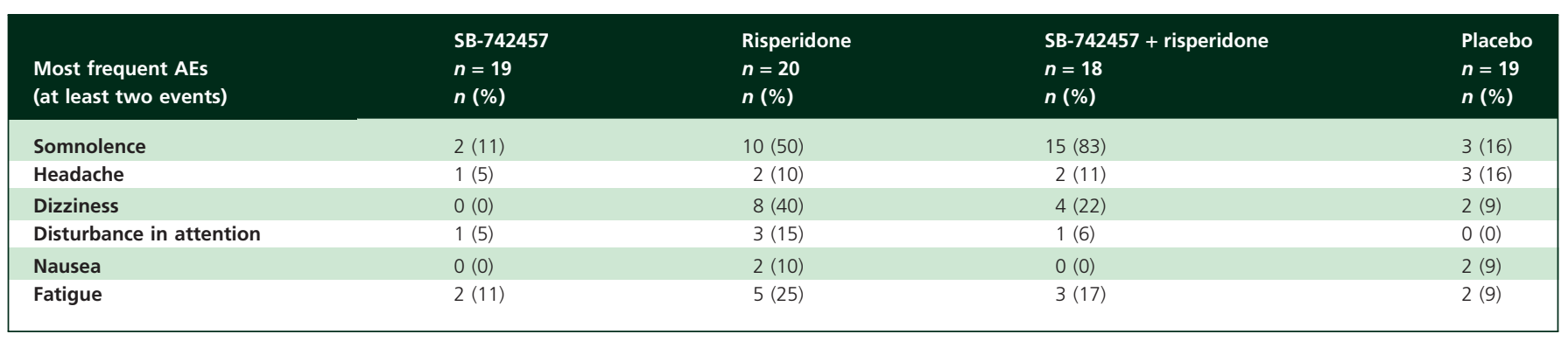

laboratory parameters. There were no serious AEs in this trial. The reported AEs are shown in Table 1.The AEs coded as 'possibly related to the study medication' were of mild to moderate intensity and resolved spontaneously. The most frequently reported $A E$, irrespective of causality, was somnolence. More subjects experienced somnolence following SB-742457 in combination with risperidone $(83 \%)$ compared with risperidone alone (50\%). On days 8 and 9, somnolence was reported by three subjects $(16 \%)$ receiving placebo and by two (11\%) receiving SB-742457 alone. One subject, after exposure to placebo SB-742457 for 5 days, was withdrawn from the study because of the occurrence of a papular rash on chest, back, hands and arms. It was not associated with any out-of-range liver enzyme or other laboratory values and resolved without treatment after 11 days. Overall, SB-742457 $50 \mathrm{mg}$ was generally well tolerated when administered orally once daily for 11 days, and also when administered at steady state in combination with a single 2-mg oral dose of risperidone.

\section{Pharmacokinetic results}

The peak plasma concentration of risperidone was $15 \mathrm{ng} \mathrm{ml}^{-1}$ at 2.3-2.7 $\mathrm{h}$ with an elimination half-life of $\sim 4 \mathrm{~h}$. Following oral co-administration of SB-742457 $(50 \mathrm{mg})$ at steady state with a single dose of risperidone, mean increases in $C_{\max }$ were estimated for total risperidone active moiety (15\%), risperidone (19\%) and 9-hydroxyrisperidone (6\%) compared with placebo (see Figure 3). The ratio (and $90 \% \mathrm{Cls}$ ) for $C_{\max }$ were $1.19(1.04,1.35)$ for risperidone, 1.15 $(1.02,1.28)$ for the total risperidone active moiety and 1.06 $(0.96,1.17)$ for 9-hydroxyrisperidone. No substantial increases in AUC were found. Overall, co-administration of risperidone with steady state SB-742457 did not alter the pharmacokinetics of SB-742457 compared with placebo.

\section{Pharmacodynamic results}

Risperidone effects Risperidone caused a considerable number of effects on subjective, neurophysiological and performance parameters. Compared with placebo, risperidone substantially decreased saccadic peak velocity, finger tapping, adaptive tracking, delayed word recognition and

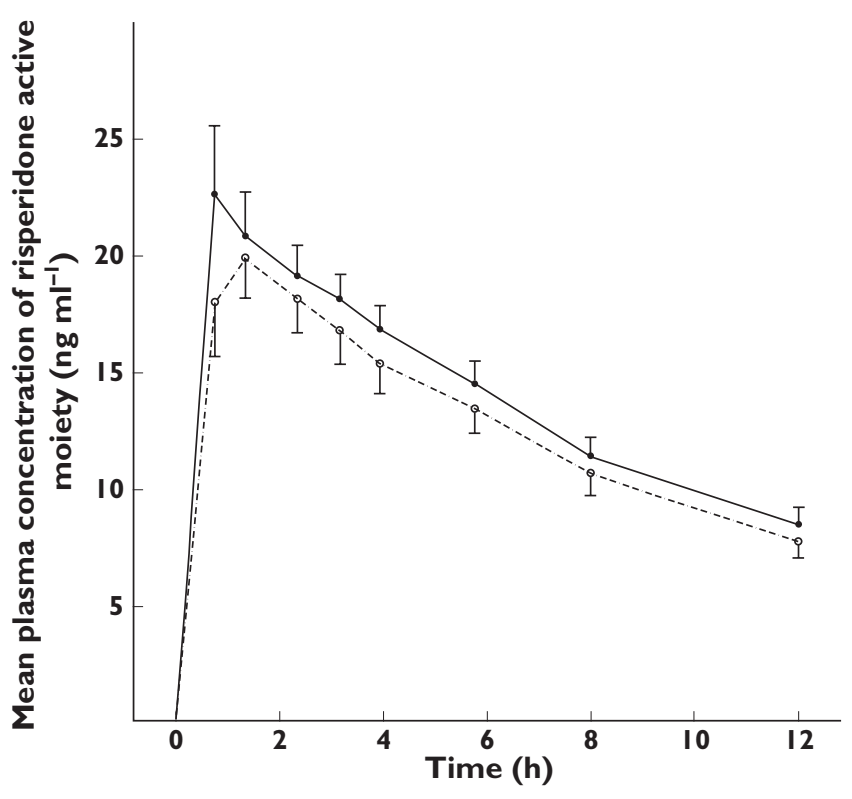

\section{Figure 3}

Mean plasma concentrations (standard errors) of risperidone active moiety in the 18 healthy volunteers who completed the study. Risperidone + SB742457 (- - $)$; Risperidone + placebo (-- $\ominus$ - $)$.

body sway, while subjective alertness and contentedness deteriorated (as assessed by the VAS Bond \& Lader) and increased EEG theta power and prolactin concentrations (differences, $95 \% \mathrm{Cl}$, and $P$ values are shown in Table 2).

SB-742457 effects When measured after single doses of risperidone or placebo on both days 8 and 9, no statistically significant differences were detected on any of the pharmacodynamic parameters between subjects daily exposed to 2 weeks of placebo and SB-742457 (data not shown).

Effects of SB-742457 co-administration on risperidone effects A single dose of risperidone in subjects during multiple daily doses of SB-742457 produced significant increases of absolute alpha $\mathrm{Pz}-\mathrm{Oz}$ and beta $\mathrm{Pz}-\mathrm{Oz}$ power 


\begin{tabular}{|c|c|c|c|c|}
\hline Parameter & $\begin{array}{l}\text { Placebo SB-742457 + } \\
\text { risperidone (day 9)* }\end{array}$ & $\begin{array}{l}\text { Placebo SB-742457 + placebo } \\
\text { risperidone (day } 8)^{*}\end{array}$ & Difference $(95 \% \mathrm{Cl})$ & $P$ value \\
\hline \multicolumn{5}{|l|}{ Saccadic eye movement } \\
\hline $\begin{array}{l}\text { Smooth pursuit eye } \\
\text { movement (\%) }\end{array}$ & 47.5 & 52.7 & $-5.2(-10.5,0.1)$ & 0.0562 \\
\hline \multicolumn{5}{|l|}{ Finger tapping } \\
\hline Average (taps $10 \mathrm{~s}^{-1}$ ) & 58.0 & 63.2 & $-5.2(-7.8,-2.6)$ & 0.0002 \\
\hline \multicolumn{5}{|l|}{ Adaptive tracking } \\
\hline \multicolumn{5}{|l|}{ VASt - Bond \& Lader } \\
\hline Alertness (mm) & 55.7 & 44.0 & $11.8(2.7,20.8)$ & 0.0124 \\
\hline Contentedness (mm) & 43.3 & 35.5 & $7.8(1.4,14.2)$ & 0.0178 \\
\hline \multicolumn{5}{|l|}{ Visual Verbal Learning Test } \\
\hline $\begin{array}{l}\text { Average reaction time } \\
\text { correct recognitions (ms) }\end{array}$ & 840.12 & 945.89 & $-105.77(-203.95,-7.59)$ & 0.0353 \\
\hline $\begin{array}{l}\text { Absolute power theta } \\
\text { Pz-Oz }(\mu \mathrm{V})\end{array}$ & 2.72 & 2.34 & ratio1.16 $(1.02,1.33)$ & 0.0299 \\
\hline \multicolumn{5}{|l|}{ Prolactin serum concentration } \\
\hline AUC (0.5-8) (ng ml-1 h) & 179.88 & 41.30 & $4.36(3.65,5.19)$ & $<0.0001$ \\
\hline$C_{\max }\left(\mathrm{ng} \mathrm{ml}^{-1}\right)$ & 53.12 & 8.19 & $6.48(5.25,8.01)$ & $<0.0001$ \\
\hline
\end{tabular}

*LSM, Least Square Means; +VAS, Visual Analogue Scale; ‡Only (almost) statistically significant values are reported; non-significant values are reported online.

compared with placebo SB-742457, while no difference was observed in other endpoints (i.e. saccadic peak velocity, smooth pursuit eye movement, finger tapping, adaptive tracking, VAS Bond \& Lader, VVLT, body sway, prolactin serum concentrations and other EEG measures; all values are shown online in Table 3).

\section{Discussion}

The $5-\mathrm{HT}_{6}$-antagonist SB-742457 is under development as a possible treatment for the cognitive symptoms in AD and possibly in schizophrenia. This study was set up to evaluate the pharmacokinetic and CNS interactions between SB-742457 and risperidone, as this $5-\mathrm{HT}_{6}$ antagonist may be used as an add-on therapy in combination with atypical antipsychotics, which may contribute to reduce cognitive impairment in some schizophrenic patients.

The results indicate that co-administration of SB-742457 with risperidone did not alter AUC (all AUC 90\% Cls were contained within the $0.80,1.25$ equivalence interval). There was a minor increase in peak exposure $\left(C_{\max }\right)$ of the total risperidone active moiety (15\%), which was caused by an elevation of risperidone concentrations (19\%) without a change of the active metabolite 9-hydroxyrisperidone. This could be related to an inhibition by SB-742457 of CYP450 3A4, which is one of the cytochrome P450 systems involved in the metabolism of risperidone [23]. Although the differences in $C_{\max }$ were statistically significant for risperidone and the active moiety, the extent of the increase was very modest and, taking into consideration the inter-subject variability, does not appear to be of any clinical relevance.

Risperidone produced its expected AE profile [50], while SB-742457 50 mg was well tolerated when administered orally once daily for 11 days either alone or in combination with a single 2-mg oral dose of risperidone. The most frequently reported $A E$, irrespective of causality, was somnolence, which occurred in a greater proportion of subjects in the presence of risperidone (with or without active SB-742457) than with placebo. However, the numbers of events were too small to draw strong conclusions.

A battery of quantitative CNS tests was used to assess the pharmacodynamic interaction between risperidone and SB-742457 in healthy volunteers. These tests were chosen for their sensitivity to classic antipsychotic agents as well as to a wide range of other CNS active drugs. Repeated daily exposure to 50-mg SB-742457 did not produce any detectable effects on any of the pharmacodynamic CNS tests when compared with placebo. Additionally, this study yielded an extensive multidimensional pharmacodynamic profile of risperidone in healthy volunteers, showing that this antipsychotic suppresses motor performance (eye-hand coordination, finger tapping and postural stability), alertness, memory 
and neurophysiological functions (saccadic eye movements and EEG power spectrum). Several of these effects confirm the effects of risperidone found in previous studies in healthy volunteers: decreased behavioural and cognitive performance, increased theta band power of the EEG spectra, decreased saccadic peak velocity and increased prolactin concentrations [50-53]. Although the observed increase in EEG theta power agrees with the effects described by De Visser et al. [22], a decrease in EEG alpha and an increase in delta power could also have been expected. When risperidone was administered to subjects exposed to daily SB-742457, the effects were generally similar to those exposed to daily placebo, except that SB-742457 combined with risperidone caused a significant increase of EEG alpha and beta power, compared with risperidone alone. Although it is difficult to assign functional significance to EEG changes, increases in EEG alpha or beta power are not typically because of sedation and have been associated with internally directed attention and increased mental load [54]. This result could be interpreted as mild subclinical arousing activity of SB-742457 in the presence of risperidone. Although this finding clearly does not constitute definitive proof, this could be considered as an indication for modulation of dopaminergic hypofunctionality by $5-\mathrm{HT}_{6}$ antagonism.

The effects were too limited to be certain of pharmacological interactions between SB-742457 and risperidone. This could be related to the unknown sensitivity of this study to detect subtle pharmacodynamic effects, because the study was powered on the pharmacokinetic outcomes. However, in other studies with similar population sizes, a similar CNS battery detected mild enhancing effects of other serotonergic agents with diverse pharmacological characteristics and for various receptor subtypes $[34,55,56]$. It is also possible that the administered dose of SB-742457 did not have any beneficial pharmacodynamic effects by itself, because of ceiling effects in healthy subjects, or functional compensation of $5-\mathrm{HT}_{6}$ receptor inhibition in this population.

In conclusion, there was no clinically relevant pharmacokinetic drug-drug interaction between SB-742457 $50 \mathrm{mg}$ and risperidone $2 \mathrm{mg}$. Repeated dosing with SB-742457 did not increase AEs or cause any pharmacodynamic effects in healthy young males, whereas a single dose of risperidone produced the expected profile of (side) effects. In general, the combination of SB-742457 and risperidone did not affect CNS function more than risperidone alone. The only statistically significant pharmacodynamic interaction was an increase of EEG alpha and beta bands, suggesting a mild arousing activity of SB-742457 on some CNS-depressive effects caused by risperidone, possibly mediated by $5-\mathrm{HT}_{6}$ receptors. The pharmacological or functional significance of these findings remains to be determined, although these interactions might indicate that SB-742457 penetrates the blood-brain barrier and modifies some effects of an antipsychotic drug.

\section{Competing Interests}

The study was executed at the Centre for Human Drug Research in Leiden, the Netherlands, with the financial support of GlaxoSmithKline of whom the authors S. Zamuner, F. Lemme and E. Merlo Pich are employees. S. Zamuner has received stocks or shares from GlaxoSmithKline as an employee.

We thank our colleagues at the Drug Metabolism and Pharmacokinetics (DMPK), GlaxoSmithKline, Ware, UK, for measuring the concentrations of SB742457, Emiliangelo Ratti for the encouragement and support for this study, Roberto Gomeni for his advice for trial design and Neil Upton for his advice during the preparation of the manuscript.

\section{REFERENCES}

1 Glennon RA. Higher-end serotonin receptors: 5-HT(5), 5-HT(6), and 5-HT(7). J Med Chem 2003; 46: 2795-812.

2 Hirst WD, Stean TO, Rogers DC, Sunter D, Pugh P, Moss SF, Bromidge SM, Riley G, Smith DR, Bartlett S, Heidbreder CA, Atkins AR, Lacroix LP, Dawson LA, Foley AG, Regan CM, Upton N. SB-399885 is a potent, selective 5-HT6 receptor antagonist with cognitive enhancing properties in aged rat water maze and novel object recognition models. Eur J Pharmacol 2006; 553: 109-19.

3 Li Z, Huang M, Prus AJ, Dai J, Meltzer HY. 5-HT6 receptor antagonist SB-399885 potentiates haloperidol and risperidone-induced dopamine efflux in the medial prefrontal cortex or hippocampus. Brain Res 2007; 1134: 70-8.

4 Pouzet B, Didriksen M, Arnt J. Effects of the 5-HT(6) receptor antagonist, SB-271046, in animal models for schizophrenia. Pharmacol Biochem Behav 2002; 71: 635-43.

5 Riemer C, Borroni E, Levet-Trafit B, Martin JR, Poli S, Porter $\mathrm{RH}$, Bos M. Influence of the 5-HT6 receptor on acetylcholine release in the cortex: pharmacological characterization of

4-(2-bromo-6-pyrrolidin-1-ylpyridine-4-sulfonyl)phenylamine, a potent and selective 5-HT6 receptor antagonist. J Med Chem 2003; 46: 1273-6.

6 Routledge C, Bromidge SM, Moss SF, Newman H, Riley G, Hagan JJ. Characterisation of SB-271046: a potent and selective 5-HT6 receptor antagonist. Br J Pharmacol 2000; 130: 1606-12.

7 Woolley ML, Marsden CA, Sleight AJ, Fone KC. Reversal of a cholinergic-induced deficit in a rodent model of recognition memory by the selective 5-HT6 receptor antagonist, Ro 04-6790. Psychopharmacology (Berl) 2003; 170: 358-67.

8 Hirst WD, Abrahamsen B, Blaney FE, Calver AR, Aloj L, Price GW, Medhurst AD. Differences in the central nervous system distribution and pharmacology of the mouse 5-hydroxytryptamine-6 receptor compared with rat and human receptors investigated by radioligand binding, 
site-directed mutagenesis, and molecular modeling. Mol Pharmacol 2003; 64: 1295-308.

9 Bourson A, Borroni E, Austin RH, Monsma FJ Jr, Sleight AJ. Determination of the role of the 5-HT6 receptor in the rat brain: a study using antisense oligonucleotides. J Pharmacol Exp Ther 1995; 274: 173-80.

10 Bourson A, Boess FG, Bos M, Sleight AJ. Involvement of 5 -HT6 receptors in nigro-striatal function in rodents. Br J Pharmacol 1998; 125: 1562-6.

11 Gerard C, Martres MP, Lefevre K, Miquel MC, Verge D, Lanfumey L, Doucet E, Hamon M, el Mestikawy S. Immuno-localization of serotonin 5-HT6 receptor-like material in the rat central nervous system. Brain Res 1997; 746: 207-19.

12 Mitchell ES, Neumaier JF. 5-HT6 receptors: a novel target for cognitive enhancement. Pharmacol Ther 2005; 108: 320-33.

13 Russell MG, Dias R. Memories are made of this (perhaps): a review of serotonin $5-\mathrm{HT}(6)$ receptor ligands and their biological functions. Curr Top Med Chem 2002; 2: 643-54.

14 Upton N, Chuang TT, Hunter AJ, Virley DJ. 5-HT6 receptor antagonists as novel cognitive enhancing agents for Alzheimer's disease. Neurotherapeutics 2008; 5: 458-69.

15 Geldenhuys WJ, Van der Schyf CJ. The serotonin 5-HT6 receptor: a viable drug target for treating cognitive deficits in Alzheimer's disease. Expert Rev Neurother 2009; 9: 1073-85.

16 East SZ, Burnet PW, Leslie RA, Roberts JC, Harrison PJ. 5-HT6 receptor binding sites in schizophrenia and following antipsychotic drug administration: autoradiographic studies with [125I]SB-258585. Synapse 2002; 45: 191-9.

17 Frederick JA, Meador-Woodruff JH. Effects of clozapine and haloperidol on 5-HT6 receptor mRNA levels in rat brain. Schizophr Res 1999; 38: 7-12.

18 Maher-Edwards G, Dixon R, Hunter J, Gold M, Hopton G, Jacobs G, Hunter J, Williams P. SB-742457 and donepezil in Alzheimer disease: a randomized, placebo-controlled study. Int J Geriatr Psychiatry 2010 Sep 24. [Epub ahead of print].

19 Chuang ATT, Foley A, Pugh PL, Sunter D, Tong X, Regan C, Dawson LA, Medhurst AD, Upton N. 5-HT6 receptor antagonist SB-742457 as a novel cognitive enhancing agent for Alzheimer's disease. Alzheimers Dement 2006; 2: S631-2.

20 Roth BL, Hanizavareh SM, Blum AE. Serotonin receptors represent highly favorable molecular targets for cognitive enhancement in schizophrenia and other disorders. Psychopharmacology (Berl) 2004; 174: 17-24.

21 Keefe RS, Bilder RM, Davis SM, Harvey PD, Palmer BW, Gold JM, Meltzer HY, Green MF, Capuano G, Stroup TS, McEvoy JP, Swartz MS, Rosenheck RA, Perkins DO, Davis CE, Hsiao JK, Lieberman JA. Neurocognitive effects of antipsychotic medications in patients with chronic schizophrenia in the CATIE Trial. Arch Gen Psychiatry 2007; 64: 633-47.

22 de Visser SJ, van der Post JP, Pieters MS, Cohen AF, van Gerven JM. Biomarkers for the effects of antipsychotic drugs in healthy volunteers. Br J Clin Pharmacol 2001; 51: 119-32.
23 Fang J, Bourin M, Baker GB. Metabolism of risperidone to 9-hydroxyrisperidone by human cytochromes P450 2D6 and 3A4. Naunyn Schmiedebergs Arch Pharmacol 1999; 359: 147-51.

24 Heykants J, Huang ML, Mannens G, Meuldermans W, Snoeck E, Van Beijsterveldt L, Van Peer A, Woestenborghs R. The pharmacokinetics of risperidone in humans: a summary. J Clin Psychiatry 1994; 55 (Suppl.): 13-7.

25 Causon R, Allanson J. Validation of an analytical method for the determination of risperidone and 9-hydroxyrisperidone in human plasma using protein precipitation and liquid chromatography with tandem mass spectrometric detection. York Bioanalytical Solutions Study Number YAY/047. DNG number:WD2005/00549/00. 2008.

26 Cohen AF, Ashby L, Crowley D, Land G, Peck AW, Miller AA. Lamotrigine (BW430C), a potential anticonvulsant. Effects on the central nervous system in comparison with phenytoin and diazepam. Br J Clin Pharmacol 1985; 20:619-29.

27 Sobczak S, Honig A, Schmitt JA, Riedel WJ. Pronounced cognitive deficits following an intravenous L-tryptophan challenge in first-degree relatives of bipolar patients compared to healthy controls. Neuropsychopharmacology 2003; 28: 711-9.

28 Wright BM. A simple mechanical ataxia-meter. J Physiol 1971; 218: 27P-28P.

29 Liem-Moolenaar M, Gray F, de Visser S, Franson K, Schoemaker R, Schmitt J, Cohen A, van Gerven J. Psychomotor and cognitive effects of a single oral dose of talnetant (SB223412) in healthy volunteers compared with placebo or haloperidol. J Psychopharmacol 2010; 24: 73-82.

30 van Steveninck AL, Schoemaker HC, Pieters MS, Kroon R, Breimer DD, Cohen AF. A comparison of the sensitivities of adaptive tracking, eye movement analysis and visual analog lines to the effects of incremental doses of temazepam in healthy volunteers. Clin Pharmacol Ther 1991; 50: 172-80.

31 van Steveninck AL, van Berckel BN, Schoemaker RC, Breimer DD, van Gerven JM, Cohen AF. The sensitivity of pharmacodynamic tests for the central nervous system effects of drugs on the effects of sleep deprivation. J Psychopharmacol 1999; 13: 10-7.

32 de Haas SL, de Visser SJ, van der Post JP, de Smet M, Schoemaker RC, Rijnbeek B, Cohen AF, Vega JM, Agrawal NG, Goel TV, Simpson RC, Pearson LK, Li S, Hesney M, Murphy MG, van Gerven JM. Pharmacodynamic and pharmacokinetic effects of TPA023, a GABA(A) alpha(2,3) subtype-selective agonist, compared to lorazepam and placebo in healthy volunteers. J Psychopharmacol 2007; 21: 374-83.

33 de Visser SJ, van der Post JP, de Waal PP, Cornet F, Cohen AF, van Gerven JM. Biomarkers for the effects of benzodiazepines in healthy volunteers. Br J Clin Pharmacol 2003; 55: 39-50.

34 Gijsman HJ, van Gerven JM, Verkes RJ, Schoemaker RC, Pieters MS, Pennings EJ, Hessing TJ, Cohen AF. Saccadic peak velocity and EEG as end-points for a serotonergic challenge test. Hum Psychopharmacol 2002; 17: 83-9. 
35 de Visser SJ, van Gerven JM, Schoemaker RC, Cohen AF. Concentration-effect relationships of two infusion rates of the imidazoline antihypertensive agent rilmenidine for blood pressure and development of side-effects in healthy subjects. Br J Clin Pharmacol 2001; 51:423-8.

36 Kemme MJ, vd Post JP, Schoemaker RC, Straub M, Cohen AF, van Gerven JM. Central nervous system effects of moxonidine experimental sustained release formulation in patients with mild to moderate essential hypertension. $\mathrm{Br} \mathrm{J}$ Clin Pharmacol 2003; 55: 518-25.

37 van der Post JP, de Visser SJ, Schoemaker RC, Cohen AF, van Gerven JM. Pharmacokinetic/pharmacodynamic assessment of tolerance to central nervous system effects of a $3 \mathrm{mg}$ sustained release tablet of rilmenidine in hypertensive patients. J Psychopharmacol 2004; 18: 221-7.

38 van Steveninck AL. Methods of assessment of central nervous system effects of drugs in man. Thesis. Leiden University, the Netherlands 1993.

39 Borland RG, Nicholson AN. Visual motor co-ordination and dynamic visual acuity. Br J Clin Pharmacol 1984; 18 (Suppl. 1): 69S-72S.

40 Zuurman L, Roy C, Schoemaker RC, Hazekamp A, Den Hartigh J, Bender JCME, Verpoorte R, Pinquier J-P, Cohen AF, Van Gerven JMA. Effect of intrapulmonary THC administration in humans. J Psychopharmacol 2008; 22: 707-16.

41 Norris $\mathrm{H}$. The action of sedatives on brain stem oculomotor systems in man. Neuropharmacology 1971; 10: 181-91.

42 Bond $\mathrm{A}$, Lader $\mathrm{M}$. The use of analogue scales in rating subjective feelings. Br J Med Psychol 1974; 47: 211-8.

43 de Haas SL, Schoemaker RC, Van Gerven JMA, Hoever P, Cohen AF, Dingemanse J. Pharmacokinetics, pharmacodynamics, and the pharmacokinetic/pharmacodynamic relationship of zolpidem in healthy subjects. J Psychopharmacol 2010; 24: 1619-29.

44 Bowdle TA, Radant AD, Cowley DS, Kharasch ED, Strassman RJ, Roy-Byrne PP. Psychedelic effects of ketamine in healthy volunteers: relationship to steady-state plasma concentrations. Anesthesiology 1998; 88: 82-8.

45 Andrew JM. Delinquents and the tapping test. J Clin Psychol 1977; 33: 786-91.

46 Schmitt JAJ, Jorissen BL, Sobczak S, van Boxtel MPJ, Hogervorst E, Deutz NEP, Riedel WJ. Tryptophan depletion impairs memory consolidation but improves focussed attention in healthy young volunteers. J Psychopharmacol 2000; 14: 21-9.
47 Rey A. L'examen Clinique en Psychologie. Paris: Presses Universitaires de France, 1964.

48 Liem-Moolenaar M, Zoethout R, de Boer P, Schmidt M, de Kam ML, Cohen A, Franson K, van Gerven JM. The effects of a glycine reuptake inhibitor R231857 on the central nervous system and on scopolamine-induced impairments in cognitive and psychomotor function in healthy subjects. J Psychopharmacol 2010; 24: 1681-7.

49 Amchin J, Zarycranski W, Taylor KP, Albano D, Klockowski PM. Effect of venlafaxine on the pharmacokinetics of risperidone. J Clin Pharmacol 1999; 39 : 297-309.

50 Hughes AM, Lynch P, Rhodes J, Ervine CM, Yates RA. Electroencephalographic and psychomotor effects of chlorpromazine and risperidone relative to placebo in normal healthy volunteers. Br J Clin Pharmacol 1999; 48: 323-30.

51 Nakagami T, Yasui-Furukori N, Saito M, Tateishi T, Kaneo S. Effect of verapamil on pharmacokinetics and pharmacodynamics of risperidone: in vivo evidence of involvement of P-glycoprotein in risperidone disposition. Clin Pharmacol Ther 2005; 78: 43-51.

52 Artaloytia JF, Arango C, Lahti A, Sanz J, Pascual A, Cubero P, Prieto $D$, Palomo T. Negative signs and symptoms secondary to antipsychotics: a double-blind, randomized trial of a single dose of placebo, haloperidol, and risperidone in healthy volunteers. Am J Psychiatry 2006; 163: 488-93.

53 Barrett SL, Bell R, Watson D, King DJ. Effects of amisulpride, risperidone and chlorpromazine on auditory and visual latent inhibition, prepulse inhibition, executive function and eye movements in healthy volunteers. J Psychopharmacol 2004; 18: 156-72.

54 Cooper NR, Croft RJ, Dominey SJ, Burgess AP, Gruzelier JH. Paradox lost? Exploring the role of alpha oscillations during externally vs. internally directed attention and the implications for idling and inhibition hypotheses. Int J Psychophysiol 2003; 47: 65-74.

55 van der Post JP, Schram MT, Schoemaker RC, Pieters MS, Fuseau E, Pereira A, Baggen S, Cohen AF, van Gerven JM. CNS effects of sumatriptan and rizatriptan in healthy female volunteers. Cephalalgia 2002; 22: 271-81.

56 Dumont GJ, de Visser SJ, Cohen AF, van Gerven JM. Biomarkers for the effects of selective serotonin reuptake inhibitors (SSRIs) in healthy subjects. Br J Clin Pharmacol 2005; 59: 495-510. 